ARTIGO

\title{
Os discursos acadêmico-científicos voltados à internacionalização dos programas de pós-graduação
}

\author{
Michele Silva Costa Sousa' (D) \\ Ângela Francine Fuzal (D)
}

RESUMO

Ações específicas de internacionalização do ensino da pós-graduação brasileira são, cada vez mais, recorrentes de acordo com as prioridades da gestão universitária. Nesse contexto, o objetivo deste estudo foi analisar os discursos acadêmico- científicos, voltados à internacionalização dos Programas de Pós-Graduação (PPGs), por meio de textos normativos das instituições oficiais financiadoras de pesquisa e pela percepção dos coordenadores de PPG da Universidade Federal do Tocantins (UFT). A pesquisa é caracterizada como qualitativa-quantitativa de cunho interpretativista, na qual utilizou-se de procedimentos investigativos de base documental, acrescidos de dados provenientes da aplicação de questionário junto aos PPGs da UFT. Os resultados apontam indícios do letramento autônomo nas práticas de internacionalização dos PPGs analisados, que têm como característica a concepção da escrita adequada a padrões estabelecidos.

PALAVRAS-CHAVE

letramentos acadêmicos; Capes; pós-graduação.

'Universidade Federal do Tocantins, Porto Nacional, TO, Brasil. 


\title{
ACADEMIC-SCIENTIFIC DISCOURSES AIMED AT THE INTERNATIONALIZATION OF GRADUATE PROGRAMS
}

\begin{abstract}
Specific actions for the internationalization of Brazilian graduate education are increasingly recurring, according to the priorities of university management. In this context, the objective of the present study is to analyze the academic-scientific discourses, aimed at the internationalization of Graduate Programs (GP) with normative texts from official research funding institutions and the perception of GP coordinators at Universidade Federal do Tocantins (UFT). Research is characterized as qualitative-quantitative, of an interpretative nature, in which documentary-based investigative procedures were used, besides data from the application of a questionnaire with UFT's GP. The results point to evidence of autonomous literacy in the internationalization practices of the analyzed GP, which has the characteristic of conceiving writing appropriate to established standards.
\end{abstract}

KEYWORDS

academic literacies; CAPES; graduate programs.

\section{DISCURSOS ACADÉMICO-CIENTÍFICOS ORIENTADOS A LA INTERNACIONALIZACIÓN DE LOS PROGRAMAS DE POSGRADO}

\section{RESUMEN}

Las acciones específicas para la internacionalización de la educación de posgrado brasileña son cada vez más recurrentes de acuerdo con las prioridades de la gestión universitaria. En este contexto, el objetivo de este estudio es analizar los discursos académico-científicos, orientados a la internacionalización de los Programas de Posgrado (PPG), a través de textos normativos de instituciones oficiales de financiación de la investigación y la percepción de los coordinadores de PPG en la Universidad Federal de Tocantins (UFT). La investigación se caracteriza por ser cualitativa-cuantitativa de naturaleza interpretativa, en la que se utilizaron procedimientos de investigación basados en documentales, más datos de la aplicación de un cuestionario con la PPG de UFG. Los resultados apuntan a evidencia de alfabetización autónoma en las prácticas de internacionalización de la PPG analizada, que tiene como característica la concepción de la escritura adecuada a los estándares establecidos.

PALABRAS CLAVE

alfabetizaciones académicas; Capes; posgraduación. 


\section{INTRODUÇÃO}

A justificativa que baliza a importância deste estudo está pautada no ritmo crescente de ações estratégicas de internacionalização que vêm se incorporando no meio universitário, influenciado principalmente pelo processo de globalização. Segundo a Coordenação de Aperfeiçoamento de Pessoal de Nível Superior (Capes, 2017), no Brasil, o processo de internacionalização nas instituições de ensino não é mais incipiente, com tendência à internacionalização passiva, com baixas taxas de atração de profissionais internacionais. Diante dessa situação, fazem-se necessários ajustes para tornar mais eficiente o potencial dos estudantes por meio do aperfeiçoamento do conhecimento acadêmico, o que permite não só a viabilização da internacionalização passiva, mas também ativa.

Assim sendo, os estudos do letramento acadêmico podem contribuir para identificar o que tem sido praticado pelos PPGs em relação à escrita universitária $\mathrm{e}$, possivelmente, sugerir ações complementares para a disseminação da produção científica e, consequentemente, a promoção da internacionalização.

Algumas práticas de letramento acadêmico estão sendo institucionalizadas no país com vistas a atender às demandas decorrentes da internacionalização, tais como as experiências dos laboratórios de letramento, na Universidade de São Paulo (USP) e na Universidade Federal de Santa Maria (UFSM), que proporcionam o desenvolvimento da habilidade de produção acadêmica nas línguas inglesa, portuguesa e francesa para fins de leitura, assimilação de conteúdo e, sobretudo, publicação de artigos científicos nessas línguas (Ferreira e Lousada, 2016).

Assim, acredita-se, neste estudo, que é possível analisar as práticas de letramento acadêmico, no contexto da internacionalização dos PPGs, a partir da observação de eventos de letramento materializados sob a forma dos gêneros que são requisitados pelas agências de fomento, que favorecem a internacionalização dessa modalidade de ensino (e também por meio dos relatos dos informantes de cada programa). Nesse sentido, o objetivo deste estudo foi analisar os discursos acadêmico-científicos, voltados à internacionalização dos $\mathrm{PPG}$ s, por meio de textos normativos das instituições oficiais financiadoras de pesquisa, principalmente da Capes, e pela percepção dos coordenadores de PPG da UFT.

A pesquisa é caracterizada como qualitativa-quantitativa de cunho interpretativista, na qual utilizou-se de procedimentos investigativos de base documental, acrescidos de dados provenientes da aplicação de questionário junto aos PPGs da UFT.

\section{OS ESTUDOS DO LETRAMENTO E OS NOVOS ESTUDOS DO LETRAMENTO}

O conceito de letramento emergiu da palavra inglesa literacy (que quer dizer letrado), resultante de uma realidade na qual não basta apenas saber ler e escrever, mas responder às práticas sociais que usam a leitura e a escrita. Ou seja, o sujeito letrado não é somente o indivíduo que é versado em letras ou literaturas, mas aquele que, além de dominar a leitura e a escrita, faz uso competente e frequente de ambas (Justo e Rubio, 2013). 
Marcuschi (2001) corrobora ao informar sobre a existência de letramentos sociais que não têm equivalência na aquisição da escrita, pois surgem além do espaço escolar. Por sua vez, Batista-Santos (2017) assinala que o referido conceito envolve diversos fatores que podem influenciá-lo, o que confere ao termo múltiplas definições e, por isso, não há conceito único e claro que contemple os aspectos que o fenômeno abarca. Para isso, é preciso "refletir criticamente sobre o fato de que cada indivíduo ou comunidade social, independentemente do seu nível de letramento, possui entendimentos de mundo em relação à escrita e sua utilização nas práticas linguageiras" (Batista-Santos, 2017, p. 91-92).

Nessa mesma direção, Kleiman (1995, p. 19) assinala que o termo letramento está relacionado a "um conjunto de práticas sociais que usam a escrita, enquanto sistema simbólico e enquanto tecnologia, em contextos específicos, para fins específicos". Essa definição demonstra o quanto o conceito de letramento pode se associar às imensuráveis possibilidades de uso da escrita, resultado das diferentes práticas sociais que incorporam essa modalidade de linguagem em contextos peculiares. Sendo assim, configurado como um fenômeno complexo, é possível extrapolar o campo escolar (ou seja, do letramento escolar) e abordar outros tipos de letramento: acadêmico, familiar, profissional, religioso, digital, musical, literário, dentre outros (Oliveira, 2015). Apesar de não haver uma definição padronizada, Soares (2009) explana que as práticas de letramento têm inúmeras competências, tais como:

Capacidade de ler ou escrever para atingir diferentes objetivos - para informar ou informar-se, para interagir com outros, para imergir no imaginário, no estético, para ampliar conhecimentos, para seduzir ou induzir, para divertir-se, para orientar-se, para apoio à memória (...); habilidades de interpretar e produzir diferentes tipos de gêneros de textos; habilidades de orientar-se pelos protocolos de leitura que marcam o texto ou de lançar mão desses protocolos, ao escrever; atitudes de inserção efetiva no mundo da escrita, tendo interesse e prazer em ler e escrever, sabendo utilizar a escrita para encontrar ou fornecer informações e conhecimentos, escrevendo ou lendo de forma diferenciada, segundo as circunstâncias, os objetivos, o interlocutor. (Soares, 2009, p. 91-92)

Desse modo, é possível compreender que o letramento, a partir da relação do uso que determinado sujeito (ou determinado grupo) estabelece com a escrita, implica outro tipo de compreensão focado nas práticas de letramentos orientadas à luz da abordagem dos Novos Estudos do Letramento (NEL). Com isso, as práticas de letramento são enredos observáveis que se estruturam e se constituem por meio das práticas sociais (Street, 2010).

Para melhor avaliação das práticas de letramento, Street (2009) propõe dois modelos de letramento: o autônomo e o ideológico. No modelo autônomo, a ênfase é na técnica, com habilidades atreladas à (de)codificação da leitura e da escrita. Na perspectiva de Russell et al. (2009), esse modelo é visto como uma habilidade descontextualizada e única, que pode ser transferida para diferentes contextos sem dificuldades significativas.

No modelo ideológico, o letramento é observado de forma mais ampla, ao compreender a diversidade das práticas sociais cotidianas, pois são dependentes da 
ideologia que permeia o contexto em que se insere e das tecnologias disponíveis. Dessa forma, é sob o contexto do letramento como uma prática social, e não como uma habilidade técnica ou neutra, que esse modelo se destaca (Street, 2003). Para Marcuschi (2001, p. 4), a vantagem desse modelo é o direcionamento para as "práticas de letramento na reprodução ou na ameaça das estruturas de poder na sociedade”. Assim,

o letramento não se desvincula do contexto cultural e social no qual é construído, bem como do significado atribuído à escrita pelas pessoas e das relações de poder que regem os seus usos, de modo que a junção desses fatores resulta em letramentos múltiplos, que variam de comunidade para comunidade, por conta das condições socioeconômicas, culturais e políticas que as influenciam. (Oliveira, 2015, p. 123)

O ambiente universitário, por exemplo, é permeado por distintas práticas sociais nas quais existe o envolvimento de sujeitos letrados que evidenciam especificidades de leitura e escrita de acordo com a área a que pertencem, o que propicia a construção de novas relações advindas das necessidades de influência dessa interação (Batista-Santos, 2017). Ou seja, o que é produzido na academia tem características peculiares de acordo com a área de conhecimento a que pertence. Por isso o letramento do tipo acadêmico tem indícios da perspectiva ideológica.

Com isso, é possível relacionar que o modelo ideológico está imbricado nos NEL, ao pressupor que os indivíduos (e os seus grupos sociais) são considerados heterogêneos e que a interação entre eles ocorre de maneiras bastante diversas (Kleiman, 2007). Dessa forma, a literatura dos NEL estabeleceu nova maneira de interpretar o letramento acadêmico ${ }^{1}$ (academic literacy), como variável dependente dos contextos sociais pelos quais a linguagem escrita se inscreve. Em outras palavras, infere-se que o NEL compreende o letramento como prática social (Gee, 1996).

Para Oliveira (2015), os primeiros autores a formularem a concepção de letramento como prática social foram Scribner e Cole (1981), considerados importantes teóricos para a disseminação da abordagem dos NEL. Assim, a corrente teórica dos NEL emergiu, no ano de 1984, a partir da obra de Street (1984) intitulada: Literacy in Theory and Practice, que introduziu as primeiras discussões sobre o NEL.

No Brasil, tanto essa obra quanto essa abordagem foram bastante difundidas por Kleiman (1995) e vêm orientando diversas investigações na área da Linguística Aplicada no que concerne às práticas e aos eventos de letramentos escolar, envolvendo perspectivas sobre docentes, discentes e não escolares, além de estudos na esfera universitária, denominados de "letramento(s) acadêmico(s)" (Miranda, 2015).

Segundo Rojo (2009), a abordagem dos NEL tem constatado a heterogeneidade das práticas de leitura, escrita e uso da linguagem, em geral, em sociedades letradas e tem permeado características socioculturais no contexto das práticas de letramento. Já para Street (2003), o diferencial dos NEL está no enfoque não somente na aquisição

1 O letramento acadêmico destacou-se no campo dos Novos Estudos do Letramento, ao final dos anos 1980, no Reino Unido, utilizando-se da etnografia para abordar práticas letradas que ocorriam no âmbito universitário (Fiad e Miranda, 2014). 
de habilidades, como ocorre nas correntes dominantes, mas também, em especial, no tratamento que é dado para o letramento como prática social.

Por sua vez, Heath (1982, p. 50) define a abordagem dos NEL como "qualquer situação na qual o texto escrito é parte constitutiva da natureza das interações dos participantes e de seus processos interpretativos". Ao referenciar essa autora, Oliveira (2015) contribui para o debate ao discorrer que os eventos ${ }^{2}$ de letramento retratam ocasiões palpáveis nas quais a linguagem escrita tem o papel de mediar as interações sociais e os processos interpretativos dos partícipes do processo.

Portanto, a reincidência dos eventos de letramento, no decorrer do tempo, transforma-se em práticas que, para serem notadas, tornam imprescindível sua descrição sistemática por meio da observância do contexto da interação, dos participantes, dos textos, dos recursos materiais utilizados, das ações dos participantes durante o evento, das sequências, dentre outros (Street e Lefstein, 2007).

\section{A VERTENTE DO LETRAMENTO ACADÊMICO}

Na conjuntura da qual advém o letramento acadêmico está situada a expansão da educação superior, fenômeno que ocorreu inicialmente, no fim da década de 1960 e início dos anos de 1970, nos Estados Unidos, com a necessidade de reestruturação do ensino da escrita em função do aumento da comunidade estudantil universitária (Bazerman e Prior, 2007).

Nesse contexto, existiram duas tendências que contribuíram significativamente para o estabelecimento do letramento acadêmico. A primeira foi influenciada pelo Writing Across the Curriculum (WAC), movimento pedagógico americano que buscou inserir a escrita nas disciplinas nos currículos acadêmicos. Enquanto a segunda tendência destacou o ensino da escrita em situações específicas de cada disciplina, na qual tanto os docentes quanto os discentes desenvolveram consciência sobre a importância da escrita e sua funcionalidade (Russell et al., 2009).

No final da década de 1980 e início de 1990, ocorreu, no Reino Unido, a expansão universitária, como fruto de uma ação governamental que ampliava o acesso à educação superior com vistas a incluir estudantes locais e estrangeiros. Devido às diversidades linguística, social e cultural, prospectaram-se limitações em relação à escrita acadêmica. Verificou-se que essas tinham origem no ingresso de alunos na universidade com dificuldades em relação à linguagem escrita (Lea e Street, 2006).

Para Lea e Street (1998), a crise na educação universitária, no Reino Unido, ocorreu pelas lacunas entre as expectativas dos docentes e a compreensão dos estudantes em relação às propostas de escrita. Diante das dificuldades detectadas, foram propostos modelos de letramentos acadêmicos na tentativa de se entender a escrita dos estudantes. Para isso, foram desenvolvidos três modelos de configuração da escrita na educação superior, conforme ilustra o Quadro 1.

2 O termo "eventos de letramento", empregado por Heath (1982), serviu de base para Street (1995) elaborar a noção de práticas de letramento e estabelecer as devidas relações entre os dois conceitos, conforme detalhou Oliveira (2015). 
Quadro 1 - Modelos de letramento acadêmico.

\begin{tabular}{|l|c|}
\hline Modelos & \multicolumn{1}{c|}{ Características } \\
\hline Habilidades de estudo & $\begin{array}{c}\text { Compreende a escrita e o letramento como competência própria e } \\
\text { intelectiva no contexto acadêmico. }\end{array}$ \\
\hline Socialização acadêmica & Infere que as declarações disciplinares e os gêneros são relativamente estáveis. \\
\hline Letramentos acadêmicos & Associa-se com a elaboração de significado, identidade, supremacia e autoridade. \\
\hline
\end{tabular}

Fonte: adaptado de Lea e Street (2014).

A abordagem do modelo das "Habilidades de estudo" foca os elementos da superfície da forma da língua e depreende que os discentes podem transladar sua competência de escrita e letramento de uma circunstância para outra sem perdas. Destarte, os discentes são responsáveis pelo próprio desempenho nas atividades de escrita.

O modelo de "Socialização acadêmica" pressupõe que, havendo domínio e entendimento dos princípios fundamentais de um enunciado acadêmico específico, os discentes estariam preparados para reproduzi-lo sem impasses. Enquanto os docentes teriam o papel de inserir os discentes na cultura universitária, bem como viabilizar a "Socialização acadêmica".

Finalmente, quando se trata do modelo de "Letramentos acadêmicos" este ter semelhança com o modelo de "Socialização acadêmica", leva em consideração os processos envolvidos na obtenção de usos adequados e eficientes de letramento como mais substanciais, ativos e variados, o que compreende tanto questões epistemológicas como também as relações de poder que têm como foco a identidade, os significados sociais e os conflitos ideológicos contidos nas práticas de letramento.

As teorias de letramento são frequentemente ensinadas e discutidas em alguns cursos específicos de licenciatura, o que, muitas vezes, incorre no desconhecimento dos docentes que são formados em instituições de menor abrangência. Como alternativa que visa minimizar essa situação, o governo federal tem criado políticas, como o Programa de Formação de Professores (PROFA), no qual se dá o ensino dos fundamentos teóricos das propostas curriculares por meio da publicação de volumes de divulgação científica (Kleiman, 2008).

Pesquisadores e estudiosos da área dos letramentos observaram que os professores nacionais identificaram de modo similar as experiências americana e britânica, a recorrência de dificuldades dos discentes na produção de escritos acadêmicos (Silva, 2017), "numa tentativa de separar os estudos sobre o impacto social da escrita dos estudos sobre a alfabetização, cujas conotações escolares destacam as competências individuais no uso e na prática da escrita" (Kleiman, 1995, p. 15-16).

No caso das práticas de letramento acadêmico, nos últimos anos, elas estiveram em constantes modificações e atualizações, dados os requisitos solicitados pela academia. Prova disso é que emergiu a área de letramentos acadêmicos para se referir aos diversos letramentos que são provenientes do contexto acadêmico (Lea e Street, 2006).

3 No Brasil, os estudos de letramento acadêmico tiveram início na década de 1980, advindos das áreas de conhecimento das ciências linguísticas e da educação. 
O interesse em estudar os letramentos próprios do âmbito universitário emergiu em função da expansão mundial do ensino superior, embora precise ser ainda mais bem discutido, pois, no país, duas décadas de estudos não foram suficientes para problematizar tal assunto (Gonçalves,2018). Até então, destacaram-se as práticas de escrita do contexto acadêmico e a postura discente diante delas, o que promoveu o surgimento de duas áreas de investigação: escrita por meio do currículo e letramentos acadêmicos (Oliveira, 2015).

A escrita por meio do currículo tem como principal característica a evidência de estratégias de leitura e escrita utilizadas para a produção de gêneros acadêmicos (Rose et al., 2003). Já a segunda vertente teórica, letramentos acadêmicos, leva em consideração a influência do contexto social para o ensino e a aprendizagem da escrita, acrescida das exigências disciplinares e institucionais, além de aspectos como as relações de poder ${ }^{4}$ no processo de ensino e aprendizagem (Lea e Street, 1998).

Dessa maneira, para Russell et al. (2009), a escrita no ambiente universitário se torna preponderante para referenciar o nível de aprendizagem, uma vez que está ligada aos aspectos de especialização muito mais do que na escola secundária. Enquanto isso, verifica-se que o ambiente universitário requer dos discentes ingressantes diferentes habilidades - citam-se as linguísticas, discursivas e estilísticas convertidas na modalidade escrita - que possibilitem reflexões críticas com foco na construção e aquisição de novos conhecimentos (Batista-Santos, 2017).

Estudiosos da abordagem dos letramentos acadêmicos salientam que, no processo de aprendizagem, no ensino superior, estão envolvidas, além das habilidades de leitura e escrita, aspectos de cunho epistemológico, identidade e poder (Lea e Street, 1998).

Conforme constatam Fiad (2011) e Street (2013), as investigações da área linguística vêm se preocupando, cada vez mais, com as práticas de letramento que envolvem, sobremaneira, a escrita dos discentes ingressantes na universidade, pois pressupõe-se que estes entrem na academia com habilidades e destrezas suficientes para produzir os gêneros que são requisitados.

Entretanto, o que prevalece entre os docentes no contexto acadêmico é a percepção de que os discentes ingressantes não são letrados por não empregarem de forma devida as práticas de linguagem requisitadas, seja pelo desconhecimento ou pelo acesso tardio às normas e às instruções que norteiam os trabalhos científicos (Fiad, 2011). Assim, a referida autora aponta a existência dessa situação, o que não sinaliza a concordância com essa assertiva. Outra explicação pormenorizada sobre esse cenário pode ser conferida em Oliveira (2015, p. 120-121), que relata que os

alunos trazem para essa comunidade discursiva concepções de escrita construídas não apenas na escola, mas em outros contextos (familiar, religioso, profissional etc.). Porém, nem sempre essas concepções são suficientes para que eles se engajem de modo imediato nas práticas letradas do domínio acadêmico, visto que

4 No ambiente universitário, existem diferentes relações de poder que se dão nesse contexto, por exemplo, as relações professor-aluno, professor-professor, aluno-aluno, professor-aluno-instituição, professor-aluno-comunidade científica, aluno-futura prática docente, professor-aluno-Tecnologias Digitais de Informação e Comunicação (TDIC), professor-aluno-sociedade, dentre outras que também são permeadas por relações de poder (Gee, 2001). 
precisam de tempo e ensino para se familiarizar com elas, ou seja, com os gêneros orais e escritos típicos desse contexto, que se apresentam para eles como novos, já que não tiveram acesso a eles em níveis anteriores de escolarização.

Na percepção dos docentes, como relatado por Canagarajah (1999), os discentes necessitam da aquisição de valores e convenções do discurso acadêmico em associação aos interesses de uma categoria hegemônica com fins de inserção nas práticas de escritas no âmbito universitário.

Nesse intento, Fiad (2011) aponta que o conjunto de regras, normas e modelos de produção institucionalizados pela universidade não é suficiente para a conversão social dos indivíduos envolvidos em críticos e agentes de promoção de reflexões e de transformações por meio da utilização consciente da língua.

O que efetivamente tem ocorrido é uma divergência entre o que é solicitado pelos docentes e o que é apresentado pelos discentes no que concerne à produção acadêmica. Isto é, há exigência de produções sem clarificar o que é realmente considerado no momento da correção e/ou avaliação, pois pressupõe-se que os universitários tenham conhecimento do que é requisitado na escrita acadêmica (Silva, 2017).

Como forma de minimizar os conflitos entre o que é solicitado pelos docentes e os resultados dos trabalhos que, muitas vezes, são repercussões das compreensões dos discentes, é imprescindível que aqueles explanem para estes as variáveis que são relevantes para a apreciação dos textos acadêmicos (Silva, 2017). Ao corroborar essa ideia, Fiad (2011) assinala que

precisam ficar claros os motivos pelos quais algumas práticas são privilegiadas no domínio acadêmico em detrimento de outras, qual significado determinada prática de letramento tem nesse domínio, o que significa justificar e argumentar de acordo com as convenções escriturais da academia. (Fiad, 2011, p. 363)

Com efeito, o desafio que é lançado para o discente está ancorado na busca por "novas posturas, novos modos de adquirir e expressar conhecimentos, novas atitudes, novas formas de se expressar enquadradas nos gêneros discursivos próprios desse ambiente" (Araújo e Bezerra, 2013, p. 6), uma vez que esse sujeito desenvolve habilidades linguísticas de acordo com o contexto sociocultural em que está inserido, nos quais as práticas sociais de escrita são concretizadas (Batista-Santos, 2017).

Finalmente, apreende-se que, no intuito de atender às expectativas da universidade no processo de internacionalização, os discentes, sobretudo os vinculados à pós-graduação, deparam-se com o desafio de utilizar e produzir os gêneros do discurso que circulam na academia, o que acarreta a necessidade de aprender novas linguagens sociais e práticas de letramento específicas e oficializadas pelo domínio acadêmico, que está submetido às normatizações, principalmente aquelas provenientes das agências de fomento (Fischer,2008).

\section{METODOLOGIA}

A pesquisa proposta, por abordar as práticas de letramento e sua relação com a internacionalização, em um estudo de caso, no contexto dos PPGs da UFT, é caracterizada como qualitativa-quantitativa de cunho interpretativista, na qual 
utilizou-se de procedimentos investigativos de base documental, acrescidos de dados provenientes da aplicação de questionário junto aos PPGs da UFT.

Para responder aos objetivos propostos nesta pesquisa e na perspectiva de conhecer os procedimentos investigativos de base documental, citam-se os principais documentos analisados:

- Regimento dos PPGs acadêmicos stricto sensu da UFT;

- Regimento da pós-graduação e outros documentos da Propesq-UFT que orientam os PPGs da instituição;

- Relatório da última avaliação (2017) dos PPGs pela Capes;

- Páginas eletrônicas oficiais dos PPGs da UFT conhecidas como mini-homes;

- Programas das disciplinas dos PPGs da UFT;

- Documentos das agências de fomento que tratam sobre internacionalização (ex.: editais, relatórios etc.).

Justifica-se a análise de dados secundários por ser uma técnica incentivada por cientistas, visto que possibilita ampliar a compreensão dos objetos empíricos que necessitam de contextualização, de acordo com suas especificidades, pois os documentos têm identidade própria e podem proporcionar diálogo (Lüdke e André,1986). Além da análise de dados secundários, foi utilizada a técnica do questionário para complementar as informações que possivelmente foram suprimidas em função da falta de atualização documental.

Para a organização dos dados primários e secundários, foram elaborados tabelas, quadros e gráficos com o objetivo de facilitar a visualização e o estabelecimento de imbricações analíticas entre os elementos coletados da pesquisa e os autores que respaldam este estudo.

De forma geral, nos documentos oficiais de cada PPG, foram analisados os gêneros que compõem os enunciados, advindos das agências de fomento e da Propesq-UFT, a fim de verificar como são descentralizadas as diretrizes de internacionalização e como os PPGs têm promovido ações em função de adequação aos parâmetros demandados. Ou seja, pressupõe-se que, ao receber as demandas de ações de internacionalização, os PPGs adotem atitude responsiva, na medida em que buscam se adequar, cada um de acordo com sua realidade, de maneira gradativa, aos quesitos que ainda diferem dos padrões propostos. Para isso, primeiramente, foram

5 Mini-homes são páginas dentro do site institucional da UFT (Portal UFT), com menus e layout personalizados, que reúnem conteúdos específicos sobre determinados temas ou setores acadêmicos e administrativos da universidade, e podem ser acessadas por meio de URLs amigáveis (endereços simplificados). Na prática, elas funcionam como sites próprios dos cursos, programas de pós-graduação, pró-reitorias etc., sendo o formato oferecido pela Diretoria de Comunicação (Dicom) e pela Diretoria de Tecnologia da Informação (DTI) em resposta à crescente demanda de criação de páginas institucionais da Universidade na internet (UFT, 2018). Elas são, na maioria das vezes, alimentadas pelos secretários, estagiários e terceirizados que compõem o corpo técnico dos PPGs. Como na UFT a maioria dos programas não dispõe dessa equipe técnica, devido ao número reduzido de força-tarefa em exercício, diversas vezes não é possível identificar a atualização das páginas que perfazem o site institucional, o que compromete a divulgação das ações que também favorecem a internacionalização. 
consultadas as mini-homes, a fim de identificar o que os PPGs disponibilizavam enquanto ações que levam à internacionalização de acordo com a proposta da Capes.

Por meio do acesso aos sites dos PPGs, foi possível também identificar, na maioria deles, a presença do regimento interno e fazer análises voltadas às práticas de letramento em função do que é requisitado enquanto produção acadêmica. Foi tomada como referência a discussão de forças centrípeta e centrífuga ${ }^{6}$, à luz dos pressupostos do Círculo de Bakhtin.

Em um segundo momento, foram analisados os relatórios da última avaliação da Capes junto aos PPGs da UFT, conforme as especificidades de cada área do conhecimento a que pertencem.

Por último, foi enviado questionário aos coordenadores de PPG como forma de melhor entender o que se tem feito para buscar a internacionalização por meio das práticas de letramento e completar as informações que não foram obtidas somente com os documentos secundários.

\section{RESULTADOS E DISCUSSÃO}

Nesta seção, são analisados os relatórios da última avaliação quadrienal (2013-2016), divulgada em 2017 pela Capes, referente aos PPGs da UFT, exceto em um mestrado da área de Planejamento Urbano e Regional/Demografia que não foi avaliado por ter sido criado em 2016, mas com a primeira turma iniciando em 2017. As fichas de avaliação estão estruturadas nos seguintes tópicos:

1) proposta do programa;

2) corpo docente;

3) corpo discente;

4) produção intelectual;

5) inserção social.

Desses, foram selecionados os itens 2,4 e 5 , que contêm informações relevantes que versam sobre práticas de letramento dos quais são apresentados os principais resultados no contexto da pós-graduação da UFT e sua relação com as questões que perpassam pela internacionalização. Parte-se do pressuposto, conforme delimitado pela Capes (2017), de que a internacionalização

é encorajada de uma maneira ampla, não apenas através da mobilidade de discentes e docentes, mas também na troca de ideias, na integração da dimensão internacional ao ensino, pesquisa e extensão, funções das instituições de ensino

6 Discussão mais aprofundada sobre o papel dessas forças consta em Sousa (2019). A força centrípeta "perpassa pelas especificidades unificadora e centralizadora das ideologias verbais atribuídas ao sistema da língua e à enunciação monológica. Enquanto na força centrífuga predomina a desestabilização, relativização e plasticização, ou seja, nela há o empenho em se manter as coisas variadas e apartadas umas das outras; que impelem ao movimento e está sujeita a acontecimentos potenciais e aos fatos históricos (Bakhtin, 2016 [1979])” (Sousa, 2019, p. 22). 
superior. A internacionalização pode ser entendida enquanto um processo amplo e dinâmico envolvendo ensino, pesquisa e prestação de serviços para a sociedade, além de construir um recurso para tornar a educação superior responsiva aos requisitos e desafios de uma sociedade globalizada. É o estágio mais elevado das relações internacionais entre as universidades. Conceitualmente, podemos dividi-la em dois tipos: a passiva, onde ocorre a mobilidade de docentes e discentes para o exterior; e a ativa, onde o fluxo é inverso. (Capes, 2017, p. 6)

Isso posto, verifica-se que o discurso acadêmico-científico com fins à internacionalização da Capes nem sempre está voltado às questões de mobilidade acadêmica (principalmente, docente), aos acordos firmados de cooperação técnico-científica e à publicação em revistas de alto impacto (e na língua inglesa), mas à integração da dimensão internacional entre as instituições para beneficiar a sociedade.

\section{ASPECTOS OBSERVADOS SOBRE A INSERÇÃO SOCIAL}

A inserção social do conhecimento produzido pelos PPGs está atrelada à preocupação de que os conhecimentos gerados sejam repassados com a maior brevidade possível para a sociedade em geral, em virtude dos desafios regionais, nacionais e internacionais da área em que eles estão inseridos. Considera-se que os PPGs da UFT têm papel preponderante para atuar diretamente nos enfrentamentos dos problemas da Região Norte e da Amazônia, com destaque para as especificidades do estado do Tocantins. Provavelmente, o nível de abrangência está ligado à recente criação dos PPGs da UFT.

Assim, as áreas da Capes buscam compreender o que se tem feito para dar visibilidade e transparência aos PPGs por meio da observância de como se dá a sua inserção social. Nesse intento, este estudo recorreu às avaliações da Capes no que diz respeito às variáveis analíticas: sites dos PPGs e parcerias institucionais, nos âmbitos nacional e internacional.

No período ${ }^{7}$ de coleta de dados, todas as mini-homes consultadas estavam disponíveis apenas na língua portuguesa. No entanto, houve sugestões de algumas áreas da Capes para que o PPG tivesse o site traduzido, preferencialmente, para a língua inglesa como forma de conferir mais visibilidade internacional ao curso. É importante frisar que a obrigação de ter uma página da web em outras línguas estrangeiras ocorre somente em cursos de excelência, ou seja, com nota igual ou superior a 6. Nota-se que, na área de Biodiversidade, há maior incentivo por versão em inglês, decorrente do fato de que a língua inglesa é a oficial para a propagação dos meios científicos. Embora o inglês seja a língua requisitada pela Capes para os padrões de internacionalização, a UFT recebe quantidade significativa de discentes oriundos da América Latina, decorrente, principalmente, do convênio com o Programa de Alianças para a Educação e a Capacitação (PAEC) que é resultado da cooperação entre a Organização dos Estados Americanos (OEA) e o Grupo Coimbra de Universidades Brasileiras (GCUB), o que necessitaria de atenção para que as mini-homes dos PPGs estivessem traduzidas também para a língua espanhola.

7 O período dedicado à coleta de todas as fontes de dados (mini-homes, análise dos relatórios e questionários) utilizadas neste estudo foram realizadas após a aprovação no Comitê de Etica em Pesquisa, entre os meses de fevereiro a maio de 2019. 
As páginas da web dos PPGs com informações completas permitem que a sociedade em geral possa conhecer a estrutura e o conhecimento gerado pelo curso, por meio da divulgação da produção acadêmica de docentes e discentes, além das dissertações e teses defendidas e aprovadas. Também é possível identificar o perfil dos docentes e dos discentes egressos, as disciplinas e a respectiva matriz curricular dos cursos, os projetos e as linhas de pesquisas vigentes, os grupos de pesquisa, bem como informações sobre o processo seletivo para ingresso nos PPGs e a divulgação de outros editais.

Constatou-se que apenas cinco PPGs — das áreas Biodiversidade, Biotecnologia, Geografia, Medicina Veterinária e Linguística e Literatura - tiveram seus sites avaliados, conforme o último relatório de avaliação da Capes, satisfatoriamente e sem nenhum apontamento sobre as lacunas até então identificadas. Já os demais PPGs tiveram alguma limitação, conforme é apontado no Quadro 2.

\section{Quadro 2- Lacunas identificadas nos sites dos programas de pós-graduação da Universidade Federal do Tocantins, por área de conhecimento em 2019.}

\begin{tabular}{|c|c|}
\hline Área do conhecimento & Lacunas identificadas \\
\hline Biodiversidade & * \\
\hline Biotecnologia & $*$ \\
\hline Ciência de Alimentos & Falta de informações sobre o credenciamento de docentes permanentes. \\
\hline Ciências Agrárias & $\begin{array}{l}\text { Não foram encontradas as dissertações para consulta e tampouco } \\
\text { informaçôes sobre normas para credenciamento de docentes, } \\
\text { processo seletivo, regiôes de origem dos discentes e detalhes sobre o } \\
\text { acompanhamento de egressos, além da falta de ementas das disciplinas. }\end{array}$ \\
\hline Ciências Ambientais & $*$ \\
\hline Comunicação e Informação & $\begin{array}{l}\begin{array}{l}\text { Supressão de apresentação dos projetos de pesquisa do corpo } \\
\text { docente. }\end{array} \\
\text {. }\end{array}$ \\
\hline Educação & $\begin{array}{l}\text { Não disponibilização de espaço de divulgação científica e difusão } \\
\text { do conhecimento. }\end{array}$ \\
\hline Ensino & As dissertações não foram divulgadas**. \\
\hline Geografia & $*$ \\
\hline Interdisciplinar & $\begin{array}{l}\text { Não foram encontradas informações sobre a matriz curricular, } \\
\text { esquema do curso e grupos de pesquisa. }\end{array}$ \\
\hline Letras/Linguística & As dissertações não foram divulgadas. \\
\hline Medicina Veterinária & * \\
\hline $\begin{array}{l}\text { Planejamento Urbano e } \\
\text { Regional/Demografia }\end{array}$ & $\begin{array}{c}\text { Ausência de informações sobre os financiamentos de agências } \\
\text { públicas e entidades privadas. }\end{array}$ \\
\hline Zootecnia/Recursos Pesqueiros & As dissertações não foram divulgadas. \\
\hline
\end{tabular}

*Os relatórios de avaliação da Capes não apontaram lacunas para o PPG da área correspondente; ${ }^{* *}$ conforme preconiza a Portaria no 013/2006 da Capes (Brasil, 2006). Neste caso, uma das possíveis justificativas é que dois PPGs mapeados foram criados recentemente e, por isso, ainda não têm dissertações defendidas.

Fonte: dados da dissertação: Práticas de letramentos e o processo de internacionalização de Programas de Pós-graduação na UFT, de Sousa (2019, p. 92). 
A ausência de divulgação das dissertações e teses prejudica a visibilidade do programa e sua projeção no âmbito internacional, além de limitar a pesquisa científica e a produção de novos conhecimentos tomando como referência o que já foi produzido.

Quanto às parcerias institucionais dos PPGs, os relatórios de avaliação da Capes destacam consideravelmente as nacionais em relação às internacionais. As justificativas podem estar amparadas no fato de que os PPGs da UFT são ainda relativamente recentes, em processo de amadurecimento para se inserir na dinâmica dos processos de internacionalização da pós-graduação. Também existem casos em que o PPG não informa no relatório da Capes se tem participação em programas de cooperação e intercâmbio, não sendo assim avaliado nesse quesito.

Mesmo entre as instituições brasileiras, notam-se ainda esforços para estabelecer e manter integração e cooperação técnica com outros Programas e Centros de Pesquisa que são referências na área. Recentemente, o Conselho Nacional de Desenvolvimento Científico e Tecnológico (CNPq) lançou a Chamada no 01/2019 (Brasil, 2019), na qual buscou apoiar propostas de fortalecimento da pesquisa científica e tecnológica por meio do intercâmbio e da cooperação entre PPGs stricto sensu consolidados e não consolidados para a formação de recursos humanos em áreas estratégicas com a concessão de bolsas de doutorado no país. Foram contemplados 37 estudantes, mas não foi possível identificar as instituições de origem no resultado final dessa chamada.

Os PPGs da UFT, principalmente aqueles com nota 3, têm relação muito próxima com as instituições locais e regionais. Um PPG da área de Ciências Agrárias, um Interdisciplinar, um de Medicina Veterinária e outro de Comunicação e Informação apresentaram estreita relação com as escolas de educação básica. Neste último PPG teve início a produção de documentários sobre a cultura da região com estudantes do ensino médio. Já o PPG da área de Medicina Veterinária tem promovido palestras nas escolas com a apresentação do curso de Veterinária e a atuação no mercado profissional com explicações sobre os experimentos e visitas aos laboratórios no campus ao qual pertence o programa. O jornal universitário é também distribuído nas escolas como forma de popularizar a ciência. Outros PPGs também citaram participação em bancas de defesas de dissertações e teses em outras instituições e vice-versa. Com vistas a se projetar com maior nota na avaliação procedente da Capes, verificam-se maiores esforços dos PPGs para articular parcerias com instituições consolidadas de outras regiões brasileiras e, até mesmo, internacionais. Poucos foram os relatórios de avaliações que nomearam as instituições que fizeram acordo de cooperação técnica com o PPG, exceto o da área de Biotecnologia, que citou a Universidade Federal do Paraná (UFPR), a Universidade Federal do Pará (UFPA), a Universidade Federal de Lavras (UFLA) e a Empresa Brasileira de Pesquisa Agropecuária (Embrapa).

Outro ponto fundamental identificado foi a participação dos docentes em agências de fomento. No caso do PPG da área de Zootecnia/Recursos Pesqueiros, há integrantes na Capes e no CNPq. Enquanto nos doutorados das áreas de Planejamento Urbano e Regional/Demografia e de Linguística e Literatura verificou-se a existência de docentes vinculados, mas não apontaram as instituições em que eles atuam. Também foram citadas participações recorrentes dos docentes, como, por exemplo:

- editores de periódicos;

- consultores ad hoc de periódicos nacionais e internacionais; 
- organizadores e debatedores de eventos internacionais e nacionais;

- representantes de sociedades científicas;

- representantes de entidades de classe.

Ações de internacionalização referentes à inserção social dos PPGs ainda são incipientes. Poucos foram os relatórios de avaliação dos PPGs que apontaram as instituições internacionais com as quais foram feitos acordos de cooperação.

Por meio do questionário foi possível ter melhor panorama das instituições estrangeiras que tiveram convênios oficialmente firmados com a UFT. Em três PPGs de duas áreas do conhecimento (Ciências Agrárias e Linguística e Literatura) foram indicados o convênio PAEC-OEA-GCUB em detrimento da própria instituição. Sabe-se que existem outros convênios ${ }^{8}$ firmados entre os distintos PPGs, porém, de acordo com os respondentes do questionário, foram mensurados os que estão listados no Quadro 3.

\section{Quadro 3 - Instituições estrangeiras que possuem termos de cooperação com os PPG da Universidade Federal do Tocantins em 2019.}

\begin{tabular}{|c|c|}
\hline Área do conhecimento & Instituições \\
\hline Biodiversidade & - \\
\hline Biotecnologia & - \\
\hline Ciência de Alimentos & - \\
\hline Ciências Agrárias & Universidade de Porto (Portugal), Universidad de Ciego de Avila (Cuba) \\
\hline Ciências Ambientais & $\begin{array}{l}\text { Universidad Autonoma de Madrid (Espanha), } \\
\text { University of Florida (Estados Unidos) }\end{array}$ \\
\hline Comunicação e Informação & - \\
\hline Educação & - \\
\hline Ensino & - \\
\hline Geografia & - \\
\hline Interdisciplinar & University of Florida (Estados Unidos), University of Victoria (Canadá) \\
\hline Letras/Linguística & - \\
\hline Medicina Veterinária & - \\
\hline $\begin{array}{l}\text { Planejamento Urbano e } \\
\text { Regional/Demografia }\end{array}$ & $\begin{array}{l}\text { Universidade Independente de Angola (Angola), Universidad } \\
\text { Nacional de Río Cuarto y Universidad Nacional de Villa María } \\
\text { (Argentina), Universidade de Santiago de Compostela (Espanha) }\end{array}$ \\
\hline Zootecnia/Recursos Pesqueiros & - \\
\hline
\end{tabular}

Fonte: dados da dissertação Práticas de letramentos e o processo de internacionalização de Programas de Pós-graduação na UFT, de Sousa (2019, p. 94).

8 A lista atualizada dos convênios vigentes da UFT com outras instituições de ensino estrangeiras encontra-se no site: https://ww2.uft.edu.br/index.php/coordenacao-de-relacoes-internacionais/acordos-de-cooperacao/acordos-vigentes. Acesso em: 20 ago. 2019. Nesta pesquisa, optou-se metodologicamente por elencar no Quadro 3 apenas as informações disponibilizadas pelos PPGs por meio do questionário aplicado em maio de 2019. 
A sugestão das áreas, de forma geral, é que os PPGs estejam em busca de integrações com docentes de outros programas e da realização de intercâmbios. A ideia é que possam contribuir para a produção do conhecimento e sua consequente disseminação, a fim de ampliar a interface com a comunidade na qual estão inseridos os PPGs, seja com maior interação com outras instituições de ensino e pesquisa no país e no exterior ou, ainda, com maior integração com outros setores da região. Para isso, sugere-se a organização de eventos acadêmicos de diversas naturezas para essa coesão. Ainda de forma tímida, a internacionalização é incentivada por todas as grandes áreas da Capes.

Considera-se, portanto, que as práticas de inserção social podem corroborar a interação dialógica entre os indivíduos e as produções acadêmicas, como forma de socialização das falas e feitos científicos que constituem objeto de estudo dos PPGs. Assim, os aspectos que dinamizam a linguagem como prática social e cognitiva possibilitam compreender as variáveis que tornam possível o diálogo e também suas limitações (Volóchinov, 2012).

\section{ASPECTOS OBSERVADOS SOBRE A PRODUÇÃO CIENTÍFICA}

$\mathrm{Na}$ avaliação das áreas, em termos de produção científica gerada pelos PPGs, constatou-se que a maioria tem quantidade satisfatória de produção científica em periódicos, embora em termos de qualificação ainda seja regular ou fraca, conforme são estabelecidos os critérios de cada área do conhecimento. Isso indica dificuldades para a internacionalização do PPG.

A inferência é que os programas com nota 3 estiveram em uma faixa considerada fraca para os parâmetros da área e em comparação com outros PPGs. Nas avaliações, o que mais pesou foi a baixa publicação de docentes em revistas científicas com Qualis A, ao considerar indicadores como de um PPG com doutorado da área de Linguística e Literatura, com 11,5\%, um PPG da área de Biodiversidade, com 26\%, um PPG da área de Ciências Agrárias, com 37,5\%, um PGG da área de Ciências Ambientais, com 47\%, um PPG da área de Geografia, com 45,9\%, e um PPG da área de Zootecnia/Recursos Pesqueiros, com 73,8\%. Esses dados ilustram os resultados dos relatórios de avaliação da Capes, mas não devem ser comparados entre si, uma vez que cada área tem suas próprias especificidades. Por exemplo, o PPG da área de Linguística e Literatura tem indicador baixo, se comparado com os demais PPGs da UFT, mas o programa atingiu conceito "muito bom", de acordo com os critérios estabelecidos pela referida área de conhecimento.

Dentre os PPGs da UFT, destaca-se um da área de Ciências Agrárias, no qual a média de artigos publicados em periódicos científicos equivalente ao conceito A1 foi muito boa, enquanto o percentual de docentes que publicaram pelo menos 0,7 artigo em revistas com Qualis A1 foi de 96\%. Esse critério foi um dos que beneficiaram o programa saltar de nota 4 para a 5, o único da UFT com essa nota. A Capes se utiliza das publicações para a atribuição de conceitos aos PPGs, a fim de balizar com aqueles que apresentam desempenho no âmbito internacional (Soares e Nova, 2017).

De forma geral, os PPGs com nota igual ou superior a 4 tiveram em suas avaliações apontamentos de que os docentes permanentes alcançaram a mediana que corresponde ao perfil de nota do programa, além de terem sido estimulados a 
ampliar a produção para publicações internacionais e em língua inglesa, a fim de alcançar indicadores de internacionalização.

Um dos pontos ressaltados pelas comissões de avaliação das distintas áreas do conhecimento é a importância de os PPGs terem docentes com bolsa produtividade nas modalidades em Pesquisa ou em Desenvolvimento Tecnológico e Extensão Inovadora. Isso significa que, para esses casos, os docentes considerados são aqueles que cumprem com resultados significantes de publicações acima da referência proposta pela área.

Por outro lado, em algumas avaliações foram feitas observações aos PPGs diante de limitações apresentadas no último quadriênio. $\mathrm{Na}$ área de Biodiversidade, a sugestão é que a coordenação mobilize os docentes a cadastrarem corretamente as informações solicitadas na Plataforma Lattes para minimizar os pareceres que foram dados na última avaliação da Capes, o que impediu, nessa avaliação, a quantificação do número de produtos técnicos por docente do núcleo permanente. Para a área de Comunicação e Informação, foi feito alerta sobre quando se publica exaustivamente em revista do próprio programa ou da instituição de origem, no qual o artigo sofre deságio de um estrato e o periódico também pode ser prejudicado em próximas avaliações de Qualis. Isso foi reflexo de 39\% da produção científica total do PPG da referida área direcionada às revistas da própria UFT, o que caracteriza excessiva endogenia na difusão da produção. Já o PPG da área de Ensino foi criticado por suas publicações terem indicativo de dificuldade em se inserir na própria área de conhecimento bem como pela possibilidade de incorreções no registro do relatório anual enviado à Capes. Em relação aos mestrados das áreas de Geografia e de Linguística e Literatura, foram solicitados maior empenho, na produção intelectual, de modo a divulgar os resultados de pesquisas com publicação em periódicos qualificados, e também melhor distribuição de produção qualificada entre os docentes como forma de melhorar a nota. Isso posto, considera-se que o desafio para a produção científica está muito mais na veiculação de artigos qualificados do que na quantidade de artigos publicados (Borini e Ferreira, 2015).

Esse último requisito foi bastante criticado pelas comissões de avaliação das áreas, em que se constatou, sobremaneira, que a maior parte da produção acadêmica está concentrada em pouquíssimos docentes permanentes dos PPGs, o que confere à coordenação do programa articular estratégias para minimizar essa lacuna.

Por fim, chega-se à conclusão de que a maioria dos PPGs da UFT tem regular produção em revistas indexadas no Qualis A e, ainda, com concentração em poucos docentes, embora se perceba potencial de aumento na publicação de artigos em revistas qualificadas, diante da quantidade de PPGs que foram criados recentemente. Em relação aos impactos da produção acadêmica, principalmente em termos de internacionalização, será possível mensurar com o desenvolvimento e amadurecimento dos PPGs e, concomitantemente, com a consolidação dos cursos de doutorado (para aqueles que já estão em funcionamento ou em fase de aprovação).

No que tange aos modelos de letramento propostos por Lea e Street (2014) e de acordo com os dados coletados nesta pesquisa, infere-se que a UFT está, a priori, situada no modelo de "Habilidades de estudo", pois as ações apreendidas, ainda que incipientes, estão voltadas à valorização da compreensão da escrita e do 
letramento no contexto acadêmico. Assim, para se chegar ao modelo de "Socialização acadêmica”, o PPG precisa socializar o conhecimento gerado por meio da escrita acadêmica não somente para a difusão, mas também para a publicação na língua inglesa, para ter maior abrangência internacional da produção. Finalmente, para se chegar ao modelo dos "Letramentos acadêmicos", é preciso que os PPGs possam, além de socializar o conhecimento, levar em consideração as metodologias envolvidas na obtenção de usos adequados e eficientes do letramento, o que implica aspectos epistemológicos, relações de poder, especificidades das áreas, significados sociais bem como os conflitos ideológicos imersos nas práticas de letramento e que também contribuem para o processo de internacionalização.

\section{ASPECTOS SOBRE O CORPO DOCENTE}

O corpo docente, na maioria dos PPGs da UFT avaliados pela Capes, tem experiência, perfil acadêmico e produção técnico-científica adequados. A maior parte da titulação de doutorado dos docentes foi obtida em outra instituição de ensino (ou em outro programa), pois apenas cinco PPGs da UFT têm doutorado com menos de dez anos de criação. Isso indica diversificação na formação do corpo docente. Do mesmo modo, pode-se inferir que essa formação heterogênea dos docentes corrobora que os PPGs tenham muitos coautores externos nas produções acadêmicas.

Os docentes permanentes que são bolsistas de produtividade do $\mathrm{CNPq}$ se destacam entre seus pares e, como consequência, ajudam o seu PPG a alcançar melhores avaliações. Dentre os programas da UFT que têm esse legado, até o ano de 2016, foram mapeados um docente da área de Linguística e Literatura, três da área de Ciências Ambientais, quatro em Zootecnia/Recursos pesqueiros, cinco em Biotecnologia e seis em dois PPGs da área de Ciências Agrárias.

Em linhas gerais, os docentes participam mais de intercâmbios com outras instituições nacionais, sendo pouco expressivos os intercâmbios internacionais. Dos que apontaram parcerias no âmbito internacional, destacam-se quatro áreas do conhecimento. Neste caso, nota-se que estão sendo firmados também acordos de cooperação com países (por exemplo, Estados Unidos, França, Austrália, Egito, China e Canadá) cuja língua predominante no meio científico é a inglesa, o que comunga com as diretrizes da Capes com vistas à internacionalização dos PPGs.

Quanto ao relato de recebimento de pesquisadores estrangeiros para se qualificar ou ser professor visitante, o PPG da área Interdisciplinar recebeu um professor da Universidade de Victoria, no Canadá; um PPG da área de Letras e Literatura foi de origem do Centro Nacional de Pesquisa Científica da França; e um PPG da área de Planejamento Urbano e Regional/Demografia recebeu três professores das seguintes instituições: Universidade de Santiago de Compostela, Universidade de Québec e Universidade de Illinois (Estados Unidos).

Considera-se que o Brasil dispõe de baixo índice de atração de profissionais estrangeiros diante dos inúmeros intercâmbios de docentes e discentes brasileiros para o exterior (Capes, 2017), o que caracteriza o país como de internacionalização do tipo passiva (Marrara, 2007). Tal cenário não é diferente na UFT, onde há mais emissão de docentes para o exterior do que recepção de docentes, discentes e pesquisadores estrangeiros para executar atividades junto aos PPGs. 
De acordo com os dados obtidos por questionário, é importante também frisar que os docentes estão investindo na busca por financiamento em atividades que fomentam a internacionalização, como, por exemplo, os editais de Pesquisador Visitante Especial e do Programa Ciências Sem Fronteiras, bem como a articulação de Projetos em Redes com o Programa Nacional de Cooperação Acadêmica (PROCAD).

Um ponto observado é que os PPGs que foram criados recentemente tiveram menor participação em intercâmbios com outras instituições, seja de projeção nacional ou internacional. Resultado evidente constatado que é após a primeira avaliação da Capes que os PPGs têm parâmetros mais palpáveis para articular estratégias institucionais. Assim, para melhor inserção acadêmica do corpo docente, é imprescindível estimular que eles efetivem iniciativas que favoreçam o intercâmbio em outras instituições nacionais e estrangeiras.

No que diz respeito ao financiamento de projetos científicos por meio de agências de fomento, considera-se que quase todos os PPGs articularam para angariar recursos, principalmente os advindos da Capes, do Fundo de Financiamento de Estudos de Projetos e Programas (Finep) e do CNPq, que são as principais no país. Também foram constatados projetos financiados com recurso externo. Dessa forma, pode-se afirmar que os docentes estão envolvidos em projetos de pesquisa financiados, o que demonstra capacidade de gestão e captação de financiamentos para as investigações. No caso de um PPG, averiguou-se, nesta pesquisa, que o número de projetos de pesquisa foi superior a 100, incentivado pela área de Ciências Agrárias, que sugere que os docentes tenham subprojetos de projetos mais amplos com objetivos afins.

$\mathrm{Na}$ busca por financiamentos, verificou-se, por meio de questionário, quais foram os editais que promovem a internacionalização pleiteados pelos PPGs. No âmbito da UFT, apenas três programas sinalizaram sua participação, sendo que dois (Ciências Ambientais e Linguística e Literatura) concorreram ao edital de auxílio de tradução e publicação de artigo científico e outro (Linguística e Literatura) concorreu ao de professor visitante do exterior. Neste caso, o baixo índice apontado pelos PPGs pode ser decorrente do fato de que o docente pode ter submetido individualmente e não necessariamente informado à coordenação do PPG do qual participa, não sendo, consequentemente, informado no questionário. Foi indicada ainda a participação no Programa Nacional de Cooperação Acadêmica na Amazônia (PROCAD/Amazônia) e no Programa Institucional de Internacionalização (Capes Print), embora nem a UFT nem outra instituição da Região Norte tenha sido contemplada por este último, o que reforça as desigualdades ${ }^{9}$ entre as demais

9 Segundo um levantamento da Capes (2017, p. 44), "existem, pelo menos, dois grupos distintos de IES no Brasil em termos de internacionalização. Um dos grupos (agrupamento 2), nos últimos anos, vêm se aproveitando melhor das oportunidades de fomento oferecidas, o que reflete em um maior número de bolsas implementadas, maior número de acordos de cooperação internacional, e maior número de projetos. Porém, esse grupo também possui o maior número de cursos de pós-graduação (PPG), ou seja, permite uma ação ampla da instituição. $\mathrm{O}$ outro grupo, aqui denominado agrupamento 1 , contêm o maior número de instituições, mas contêm o menor número de PPG por IES, e os menores índices de internacionalização (menor número de bolsas implementadas, acordos, projetos, etc.)". 
regiões que têm instituições mais consolidadas e a Região Norte. Tal cenário indica que o discurso acadêmico-científico das agências de fomento está mais voltado às questões de produção docente e mobilidade acadêmica incentivadas por editais.

Por outro lado, não foi indicada nenhuma ação referente ao Programa Ciência sem Fronteiras $(\mathrm{CsF})$, considerado a política mais ambiciosa no âmbito da internacionalização da Pesquisa e Desenvolvimento $(\mathrm{P} \& \mathrm{D})$ brasileira, pois conseguiu contemplar inúmeros discentes, docentes e profissionais de nível superior para treinamento em centros de pesquisa e ensino avançados no exterior (Ramos, 2018). Em um estudo sobre o CsF na UFT, Lage (2015) constatou que o programa foi um marco nas ações de internacionalização nessa instituição, pois verificou-se que, anteriormente a essa institucionalização, a acessibilidade dos discentes às mobilidades acadêmicas internacionais eram bastante restritas, principalmente pela falta de financiamento.

Quanto a ministrar disciplinas, é recomendado que todo o corpo docente permanente dos PPGs ofereça, ao menos uma vez por ano, a não ser que esteja afastado para pós-doutorado, capacitação ou outro tipo de licença. Em poucos casos foram indicadas fragilidades nesse quesito.

Os docentes, de maneira em geral, são atuantes em sociedades científicas, em composição de corpo editorial de periódicos, em comissões externas, em atuação e organização de eventos científicos, na participação em órgãos de fomento e como avaliadores ad hoc de periódicos indexados.

Conclui-se que os PPGs estão em busca de avanço na cooperação técnica para se projetar internacionalmente, por meio da articulação entre os seus docentes para a consecução de intercâmbio com outros grupos de pesquisas de instituições de renome nacionais e, principalmente, estrangeiras. Isso refletiu no aumento da captação de recursos para os projetos de pesquisa nos quais os docentes estão envolvidos e na produção de artigos com coautores das instituições parceiras. Desse modo, há tendência à instrumentalização da escrita, em uma perspectiva de letramento autônomo, uma vez que o estabelecimento de parcerias institucionais contribui para o alcance de indicadores internacionais, como o de publicação em revistas de alto impacto. Não obstante, apenas a questão da cooperação não é suficiente para afirmar que há internacionalização, tendo em vista que ela é composta por diversas práticas que devem estar em sincronia, além de ter periodicidade.

\section{CONSIDERAÇÕES}

Os resultados deste estudo constataram indícios do letramento autônomo nas práticas de internacionalização dos PPGs analisados, que têm como característica a concepção da escrita adequada a padrões, com fim determinado. As práticas de letramento acadêmico para a promoção da internacionalização na UFT ainda são tímidas, visto que não há periodicidade em ações, como oferta de disciplinas e cursos de escrita acadêmica para a publicação de revistas de veiculação no âmbito internacional, imperativo do aprimoramento da língua inglesa com fins de oportunizar a publicação em revistas de alto impacto. 
Verifica-se também que a UFT está em processo de aprimoramento de ações de internacionalização, embora os PPGs não tenham conseguido, na avaliação da Capes, atingir o conceito que indica padrão de excelência internacional, justificado também pela recente criação dessa instituição. Além disso, para se tornar uma instituição reconhecida, em âmbito internacional, é preciso ter ações mais abrangentes e periódicas, características da força centrífuga. Entretanto, constatou-se que o processo de internacionalização dos PPGs estava mais voltado ao letramento autônomo, tendo em vista que se identificou, neste trabalho de dissertação, as práticas em uma concepção voltada à escrita padronizada. Dessa forma, existe o predomínio do modelo das "Habilidades de estudo", pois os PPGs estão na fase de valorização da compreensão da escrita e do letramento no contexto acadêmico.

E importante salientar que ainda é preciso melhorar o debate sobre o que se entende por internacionalização da pós-graduação e seus impactos na sociedade. A Capes, considerada a principal agência de fomento brasileira, tem realizado levantamentos a respeito desse tema, com a finalidade de desenhar novas diretrizes para o fomento na pós-graduação. Prova disso é que foi publicado, em 2017, o diagnóstico "A internacionalização na Universidade Brasileira: resultados do questionário aplicado pela Capes"; em 2018, foi lançado o edital Capes Print; e, em 2019, foram propostas mudanças na avaliação quadrienal dos PPGs, conferindo, explicitamente, peso às ações de internacionalização.

Mesmo com as ações que ocorrem no âmbito acadêmico-científico, para potencializá-las é preciso ainda questionar: que implicações a internacionalização já trouxe para o desenvolvimento da pós-graduação? Quais efeitos pode trazer para a pesquisa? O que se sabe, em termos quantitativos, é que, nos últimos anos, com o fomento, as iniciativas de internacionalização têm proporcionado o crescimento do número de projetos de colaboração e programas no exterior, além de ter aumentado significativamente o número de bolsas de estudos no exterior, por meio das quais estrangeiros têm vindo estudar no Brasil, assim como docentes e pesquisadores brasileiros têm ido ao exterior para estudar e discutir resultados com parceiros estrangeiros.

Entretanto, com a atual fase do governo, os investimentos nessa área também têm sido cortados. Citam-se o ocorrido com o edital de bolsas do exterior do CNPq, no segundo semestre de 2019, que foi cancelado; os recursos do Capes Print, que foram pagos parcialmente, em relação ao total previsto para o ano; dentre outros editais de projetos financiados que podem vir a prejudicar a promoção da internacionalização da pós-graduação brasileira. Para tanto, é preciso observar o que foi construído e articular uma rede para que as ações de internacionalização continuem, mesmo em ritmo menor do que o dos demais anos, para que não se perca a estrutura e o know how investidos pelas agências de fomento. $\mathrm{O}$ desafio, no atual contexto, é continuar com a promoção das ações de internacionalização, tendo como foco a adequação à nova proposta de avaliação dos PPGs, socializada no Seminário de Meio Termo, promovido pela Capes, com o objetivo de evidenciar o quão importante é a internacionalização para dar visibilidade aos programas e aos seus impactos na sociedade, ainda que com limitados recursos disponíveis. 


\section{REFERÊNCIAS}

ARAÚJO, C. M.; BEZERRA, B. G. Letramentos acadêmicos: leitura e escrita de gêneros acadêmicos no primeiro ano do curso de Letras. Diálogos, n. 9, p. 5-37, 2013. https://doi.org/10.13115/2236-1499.2013v1n9p5

BATISTA-SANTOS, D. O. Letramento Acadêmico: representações de ingressantes acerca da escrita. Trama, Marechal Cândido Rondon, v. 13, n. 28, p. 86-118, 2017. https://doi.org/10.48075/rt.v13i28.15586

BAZERMAN, C.; PRIOR, P. A participação nos mundos socioletrados emergentes. In: BAZERMAN, C. (Org.). Escrita, gênero e interação social. São Paulo: Cortez, 2007. p. 150-197.

BORINI, F. M.; FERREIRA, J. Internacionalização de periódicos científicos brasileiros: estudo de caso à luz da teoria de redes e da teoria institucional. Revista Ibero-Americana de Estratégia, v. 14, n. 4, p. 24-41, 2015. https://doi.org/10.5585/ ijsm.v14i4.2252

BRASIL. Portaria no 013/2006. Institui a divulgação digital das teses e dissertações produzidas pelos programas de doutorado e mestrado reconhecidos. Brasil: Ministério da Educação, 2006. Disponível em: http://repositorio.unb.br/documentos/Portaria N13_CAPES.pdf. Acesso em: 19 abr. 2019.

BRASIL. Conselho Nacional de Desenvolvimento Científico e Tecnológico. Chamada Pública CNPq no 01/2019: Apoio à Formação de Doutores em Áreas Estratégicas. Brasil: Conselho Nacional de Desenvolvimento Científico e Tecnológico, 2019. Disponível em: https://bit.ly/3cVsSXn. Acesso em: 20 ago. 2020.

CANAGARAJAH, A. S. Contrasting literacies: appropriating academics texts. In: CANAGARAJAH, A. S. Resisting linguistic: imperialism in English teaching. Nova York: Oxford University Press, 1999. p. 147-171.

COORDENAÇÃO DE APERFEIÇOAMENTO DE PESSOAL DE NÍVEL SUPERIOR (CAPES). A internacionalização na universidade brasileira: resultados do questionário aplicado pela Capes. Brasília: Capes, 2017.

FERREIRA, M. M.; LOUSADA, E. G. Ações do laboratório de letramento acadêmico da Universidade de São Paulo: promovendo a escrita acadêmica na graduação e na pósgraduação. Ilha do Desterro, v. 69, n. 3, p. 125-140, 2016. https://doi.org/10.5007/21758026.2016v69n3p125

FIAD, R. S. A escrita na universidade. Revista da ABRALIN, v. 10, n. 4, p. 357-369, 2011. FIAD, R. S.; MIRANDA, F. D. S. S. Letramentos digitais e acadêmicos em contexto universitário: investigando práticas letradas em um curso de letras de uma universidade pública. Revista Colineares, v. 1, n. 1, p. 31-50, 2014.

FISCHER, A. Letramento acadêmico: uma perspectiva portuguesa. Acta Scientiarum: Language and Culture, Maringá, v. 30, n. 2, p. 177-187, 2008. https://doi.org/10.4025/ actascilangcult.v30i2.2334

GEE, J. P. Social linguistics and literacies: ideology in Discourses. 2. ed. Londres, Filadélfia: The Farmer Press, 1996. 
GEE, J. P. Reading as situated language: a sociocognitve perspective. Journal of Adolescent \& Adult Literacy, n. 7, p. 714-725, 2001.

GONÇALVES, B. A. Estado da arte de pesquisas sobre letramento no Brasil: como são pesquisadas agências, eventos e práticas além da escola? 2018. 189f. Dissertação (Mestrado em Letras e Linguística) - Universidade Federal de Goiás, Goiânia, 2018.

HEATH, S. B. What no bedtime story means: narrative skills at home and school. Language in Society, v. 11, n. 1, p. 49-76, 1982.

JUSTO, M. A. P. S.; RUBIO, J. A. S. Letramento: o uso da leitura e da escrita como prática social. Revista Eletrônica Saberes da Educação, v. 4, n. 1, p. 1-17, 2013.

KLEIMAN, A. B. Modelos de letramento e as práticas de alfabetização na escola. In: KLEIMAN, A. B. (org.). Os significados do letramento: uma nova perspectiva sobre a prática social da escrita. Campinas: Mercado das Letras, 1995. p. 15-61.

KLEIMAN, A. Letramento e suas implicações para o ensino de língua materna. Signo, Santa Cruz do Sul,v. 32, n. 53, p. 1-25, 2007. https://doi.org/10.17058/signo.v32i53.242 KLEIMAN, A. B. Os estudos de letramento e a formação do professor de língua materna. Linguagem em (Dis)curso, v. 8, n. 3, p. 487-517, 2008. https://doi. org/10.1590/S1518-76322008000300005

LAGE, T. S. R. Políticas de internacionalização da educação superior na região norte do Brasil: uma análise do Programa Ciência sem Fronteiras. 2015. 183f. Dissertação (Mestrado em Desenvolvimento Regional) - Universidade Federal do Tocantins, Palmas, 2015.

LEA, M. R.; STREET, B. Student writing in higher education: an academic literacies approach. Studies in Higher Education, Londres, v. 23, n. 2, p. 157-172, 1998. https:// doi.org/10.1080/03075079812331380364

LEA, M. R.; STREET, B. V.The “academic literacies" model: theory and applications. Theory into Practice Fall, v. 45, n. 4, p. 368-377, 2006. https://doi.org/10.1207/ s15430421tip4504_11

LEA, M. R.; STREET, B. V.O modelo de "letramentos acadêmicos": teoria e aplicações. Revista Filologia e Linguística Portuguesa, São Paulo, v. 16, n. 2, p. 477-493, 2014. https://doi.org/10.11606/issn.2176-9419.v16i2p477-493

LÜDKE, M.; ANDRÉ, M. E. D. A. Pesquisa em educação: abordagens qualitativas. São Paulo: EPU, 1986.

MARCUSCHI, L. A. O papel da linguística no ensino de línguas. Investigações, Recife, v. 13-14, p. 187-218, 2001.

MARRARA, T. Internacionalização da pós-graduação: objetivos, formas e avaliação.

Revista Brasileira de Pós-Graduação, Brasília, v. 4, n. 8, p. 245-262, 2007. https://doi. org/10.21713/2358-2332.2007.v4.132

MIRANDA, F. D. S. S. Letramentos (en)formados por relações dialógicas na universidade: (res)significações e refrações com tecnologias digitais. 2015. 414f. Tese (Doutorado em Linguística Aplicada) - Universidade Estadual de Campinas, Campinas, 2015. 
OLIVEIRA, E. F. Letramentos acadêmicos: o gerenciamento de vozes em resenhas e artigos científicos produzidos por alunos universitários. 2015.517f. Tese (Doutorado em Linguística Aplicada) - Universidade Estadual de Campinas, Campinas, 2015.

RAMOS, M.Y.Internacionalização da pós-graduação no Brasil: lógica e mecanismos. Educação e Pesquisa, v. 44, e161579, 2018. https://doi.org/10.1590/s15179702201706161579

ROJO, R. H. R. Letramentos múltiplos: escola e inclusão social. São Paulo: Parábola, 2009. ROSE, D. et al. Scaffolding academic reading and writing at the Koori Centre. The Australian Journal of Indigenous Education, v. 32, p. 41-50, 2003. https://doi. org/10.1017/S1326011100003811

RUSSELL, D. R. et al. Exploring notions of genre in "academic literacies" and "Writing Across the Curriculum": approaches across countries and contexts. In: BAZERMAN, C.; BONINI, A.; FIGUEIREDO, D. (Org.). Genre in a changing world. Fort Collins: The WAC Clearinghouse/West Lafayette: Parlor Press, 2009. p. 395-423.

SCRIBNER, S.; COLE, M. The psychology of literacy. Cambridge: Harvard University, 1981.

SILVA, E. M. Os mistérios que envolvem a escrita acadêmica. In: AGUSTINI, C. L.; BERTOLDO, E. S. (Org.). Incursões na escrita acadêmico-universitária: letramento, discurso, enunciação. Uberlândia: EDUFU, 2017.v. 1. p. 141-152.

SOARES, M. Letramento: um tema em três gêneros. Belo Horizonte: Autêntica, 2009. SOARES, S.V.; NOVA, S.P.C.C. Pesquisadores brasileiros que publicam em periódicos internacionais: qual sua formação acadêmica? Revista Gestão Universitária na América Latina, Florianópolis, v. 10, n. 1, p. 125-149, 2017. https://doi.org/10.5007/19834535.2017v10n1p125

SOUSA, M. S. C. Práticas de letramentos e o processo de internacionalização de Programas de Pós-graduação na UFT. 2019. Dissertação (Mestrado em Letras) Universidade Federal do Tocantins, 2019.

STREET, B. Literacy in Theory and Practice. Cambridge: Cambridge University Press, 1984.

STREET, B. V. Social literacies: critical approaches to literacy development, ethnography, and education. Londres: Longman, 1995.

STREET, B. What's "new" in New Literacy Studies? Critical approaches to literacy in theory and practice. Current Issues in Comparative Education, v. 5, n. 2, p. 77-91, 2003. STREET, B. "Hidden" features of academic paper writing. Working Papers in Educational Linguistics, v. 24, n. 1, p. 1-17, 2009.

STREET, B. 'Academic Literacies approaches to Genre'? Revista Brasileira de Linguística Aplicada, Belo Horizonte, v. 10, n. 2, p. 347-361, 2010. https://doi. org/10.1590/S1984-63982010000200004

STREET, B. V. Políticas e práticas de letramento na Inglaterra: uma perspectiva de letramentos sociais como base para uma comparação com o Brasil. Cadernos Cedes, v. 33, n. 89, p. 51-71, 2013. https://doi.org/10.1590/S0101-32622013000100004 
STREET, B.; LEFSTEIN, A. Literacy: an advanced resource book. Londres/Nova York: Routledge, 2007.

UNIVERSIDADE FEDERAL DO TOCANTINS (UFT). O que é uma "minihome"? Palmas: UFT, 2018. Disponível em: http://ww2.uft.edu.br/index.php/ perguntas-frequentes1/216-sites-e-paginas-institucionais-no-portal-uft-minihomesfaq/17163-o-que-e-uma-minihome. Acesso em: 20 ago. 2020.

VOLÓCHINOV,V.N.Marxismo efilosofia dalinguagem. 13. ed. São Paulo:Hucitec, 2012.

\section{SOBRE AS AUTORAS}

Michele Silva Costa Sousa é doutoranda em desenvolvimento regional pela Universidade Federal do Tocantins (UFT). Professora do Instituto Federal de Educação, Ciência e Tecnologia do Tocantins (IFTO).

E-mail: michele2_sc@yahoo.com.br

Ângela Francine Fuza é doutora em linguística aplicada pela Universidade Estadual de Campinas (UNICAMP). Professora da Universidade Federal do Tocantins (UFT).

E-mail: angelafuza@uft.edu.br

Conflitos de interesse: Os autores declaram que não possuem nenhum interesse comercial ou associativo que represente conflito de interesses em relação ao manuscrito.

Financiamento: $\mathrm{O}$ estudo não recebeu financiamento.

Contribuições dos autores: Curadoria de Dados, Investigação, Metodologia, Escrita Primeira Redação, Escrita — Revisão e Edição: Sousa, M.S.C. Investigação, Metodologia, Supervisão, Escrita — Revisão e Edição: Fuza, A.F.

Recebido em 6 de março de 2020 Aprovado em 10 de agosto de 2020 